\title{
A trajetória educacional, acadêmica e esportiva de jovens atletas de basquetebol:
}

\section{Uma revisão de escopo}

\author{
The educational, academic and sporting trajectory of young basketball athletes: A scope review \\ La trayectoria educativa, académica y deportiva de los jóvenes deportistas de baloncesto: Una \\ revisión del alcance
}

Recebido: 18/11/2021 | Revisado: 24/11/2021 | Aceito: 25/11/2021 | Publicado: 07/12/2021

\author{
Adair José Pereira da Rocha \\ ORCID: https://orcid.org/0000-0002-3308-121X \\ Universidade Federal do Paraná, Brasil \\ E-mail adairbasquetecuritiba@gmail.com \\ Willian Henrique Corrêa \\ ORCID: https://orcid.org/0000-0003-4490-125X \\ Universidade Federal do Paraná, Brasil \\ E-mail: willianhcorrea@hotmail.com \\ Gilson Brun \\ ORCID: https://orcid.org/0000-0002-9090-0736 \\ Universidade Federal do Paraná, Brasil \\ E-mail: gilsonbrun1@gmail.com \\ Gislaine Cristina Vagetti \\ ORCID: https://orcid.org/0000-0003-0704-1297 \\ Universidade Estadual do Paraná, Brasil \\ E-mail: gislainevagetti@hotmail.com \\ Valdomiro de Oliveira \\ ORCID: https://orcid.org/0000-0002-8709-8471 \\ Universidade Federal do Paraná, Brasil \\ E-mail: oliveirav457@gmail.com
}

\begin{abstract}
Resumo
Objetivo: mapear estudos que analisem a trajetória educacional, acadêmica e esportiva de jovens atletas de basquetebol. Método: a revisão de escopo foi realizada utilizando-se da metodologia elaborada pelo instituto Joanna Briggs (JBI) e inclui estudos realizados em pesquisas com jovens atletas de basquetebol. Foram considerados estudos publicados em inglês, espanhol ou português com um limite de data de 10 anos em documentos procedentes como artigos, dissertações e teses que foram organizados em ordem de ano crescente. Intencionalmente foram selecionados documentos governamentais de aporte ao esporte, com ênfase no basquetebol. A estratégia de busca seguiu o processo natural de rastreio de documentos, com a pesquisa feita nas bases de dados: Periódicos CAPES, BVS, SciELO, SportDiscus, Scopus, Web of Science, PubMED/ MEDLINE e ERIC. Foram usados os descritores "Ambiente Educativo", "Desenvolvimento humano" e "Basquetebol". Resultado: de 297 estudos encontrados foram selecionados 9 artigos, sendo esses estudos pontuais que retrataram o interesse da trajetória esportiva/carreira esportiva de jovens atletas de basquetebol e o ambiente em que se insere. Conclusão: dos estudos selecionados, alguns trazem o respaldo científico do ambiente por meio da teoria de Urie Bronfenbrenner (Teoria Bioecológica) e evidenciam o ambiente como incitação para o desenvolvimento ou atraso, impactando em sua trajetória educacional, acadêmica e esportiva. A maioria dos documentos utilizou uma abordagem qualitativa e todos apresentam semelhanças em sua problemática, entretanto conclui-se parcialmente que são pontuais os estudos conectando a trajetória esportiva relacionada ao ambiente do basquetebol utilizando-se do método qualitativo, nota-se ser mais incomum a existência de documentos que utilizam métodos quantitativos.
\end{abstract}

Palavras-chave: Desenvolvimento humano; Ambiente; Basquetebol; Trajetória esportiva.

\begin{abstract}
Objective: to map studies that analyze the educational, academic and sporting trajectory of young basketball athletes. Method: The scope review was carried out using the methodology developed by the Joanna Briggs Institute (JBI) and includes research studies carried out with young basketball athletes. Studies published in English, Spanish or Portuguese were considered using a date limit of 10 years in originating documents such as articles, dissertations and theses that were organized in ascending order of year. Government documents were intentionally selected to support the sport with an emphasis on basketball. The search strategy followed the natural process of document screening, with the search carried out in the following databases: CAPES, BVS, SciELO, SportDiscus, Scopus, Web of Science,
\end{abstract}


PubMED/MEDLINE and ERIC journals. The descriptors "Educational Environment", "Human development", "Basketball" were used. Results: From 297 studies found, 9 articles were selected, these being punctual studies, which portrayed the interest in the sporting trajectory/sports career of young basketball athletes and the environment in which they are inserted. Conclusion: Of the selected studies, some bring the scientific support of the environment through the theory of Urie Bronfenbrenner (Bioecological Theory) that show the environment as an incitement to development or delay, impacting their educational, academic and sports trajectory. Most documents used a qualitative approach and all have similarities in their problem, however it is partially concluded that studies connecting the sports trajectory related to the basketball environment using the qualitative method are punctual, it is noted that the existence is more unusual. documents that use quantitative methods.

Keywords: Human development; Environment; Basketball; Sport trajectory.

\section{Resumen}

Objetivo: mapear estudios que analicen la trayectoria educativa, académica y deportiva de jóvenes deportistas de baloncesto. Método: La revisión del alcance se realizó utilizando la metodología desarrollada por el Instituto Joanna Briggs (JBI) e incluye estudios de investigación realizados con jóvenes deportistas de baloncesto. Se consideraron los estudios publicados en inglés, español o portugués con fecha límite de 10 años en documentos relevantes como artículos, disertaciones y tesis que fueron organizados en orden ascendente de año. Los documentos gubernamentales fueron seleccionados intencionalmente para apoyar el deporte con énfasis en el baloncesto. La estrategia de búsqueda siguió el proceso natural de cribado de documentos, con la búsqueda realizada en las siguientes bases de datos: CAPES, BVS, SciELO, SportDiscus, Scopus, Web of Science, PubMED / MEDLINE y revistas ERIC. Se utilizaron los descriptores "Entorno educativo", "Desarrollo humano", "Baloncesto". Resultados: De los 297 estudios encontrados, se seleccionaron 9 artículos, siendo estos estudios puntuales, que retrataron el interés por la trayectoria deportiva / carrera deportiva de los jóvenes deportistas de baloncesto y el entorno en el que se insertan. Conclusión: De los estudios seleccionados, algunos aportan el sustento científico del medio ambiente a través de la teoría de Urie Bronfenbrenner (Teoría Bioecológica) que muestran el medio ambiente como una incitación al desarrollo o retraso, impactando su trayectoria educativa, académica y deportiva. La mayoría de los documentos utilizaron un enfoque cualitativo y todos tienen similitudes en su problema, sin embargo se concluye parcialmente que los estudios que relacionan la trayectoria deportiva relacionada con el ambiente del baloncesto utilizando el método cualitativo son puntuales, se observa que la existencia es más inusual. Métodos cuantitativos.

Palabras clave: Desarrollo humano; Medio ambiente; Baloncesto; Trayectoria deportiva.

\section{Introdução}

Todos os esportes coletivos são formados em equipes, que são separadas por categorias. No caso do basquetebol, que tradicionalmente, no Brasil, começa a ser praticado por crianças de 8 a 12 anos, parece existir o desejo em tornar-se um atleta, construindo sua trajetória esportiva educacional nessa fase da vida. Essa divisão de categorias pode ser compreendida temporalmente pela Federação Paranaense de Basketball (FPRB), onde os atletas iniciam nas categorias denominadas desde o sub-12 até o sub-19 como a última categoria antes de o atleta ir para um caminho profissional (Tubino, 1999; FPRB, 2021; CBB, 2021).

Na FPRB há categorias por idades, organizadas em formato crescente do sub-12 ao sub-19. Entretanto, as primeiras categorias têm um fato intrigante: a criança com 8 anos com condições físicas e com habilidade pode atuar no sub-12, ou seja, antecipa em dois a três anos o nível competitivo, aumentando consideravelmente sua trajetória no esporte.

Tal trajetória, que poderia ser registrada em documentos utilizando-se de recursos já conhecidos, instrumentos que avaliam a qualidade de vida dos atletas ou até mesmo fatos, acontecimentos de sua trajetória educacional/esportiva desde o início até o final da categoria, dados que podem, de uma certa forma, mensurar diversos aspectos, como o ambiente, está influenciando nessa cadeia (Gomes, 2018; Szeremeta, 2019).

$\mathrm{Na}$ entidade maior que rege o basquete no Brasil, a Confederação Brasileira de Basketball (CBB), ou na que rege o Basquete no Paraná, a FPRB, não se observaram estudos ou documentos que acompanhem o desenvolvimento humano, a entrada ou a evasão do esporte, ou métodos validados que registrem o ambiente do basquetebol, documentos que se forem organizados podem ajudar a compreender a trajetória esportiva, observando detalhes que ocasionaram seu fracasso ou sucesso no esporte. 
Saber quais categorias existem é algo já organizado, mas compreender quem estuda e escreve sobre o tema nos últimos 10 anos parece ser curioso para o meio esportivo, acadêmico, escolar, além de que conhecer as pesquisas e estudos sobre o tema talvez colabore com esse ecossistema (Krebs, 2006; Oliveira et al., 2020).

Foi observada a importância de saber onde estão esses estudos sobre o tema, métodos, características e populações, além de locais que estão sendo pesquisados sobre esse objeto, pois para dar um início a qualquer estudo, possuindo-se mais informações, as novas pesquisas podem ser induzidas pela lacuna de estudos pontuais, chegando a hipóteses pertinentes. Neste caso, a trajetória educacional, acadêmica do jogador de basquetebol jovem atrelada ao ambiente e ao desenvolvimento humano.

A grande parte dos documentos analisados mostra que o ambiente é favorável ou não favorável devido à falta de incentivo e de estrutura física e financeira; contudo, foram selecionados intencionalmente documentos que aportam recursos em nível municipal, estadual e nacional, sendo possível por meio deste prospecto compreender que exista impacto no ambiente através de leis que incentivam o basquetebol, dando ao leitor uma opção de conhecer formas que estejam incentivando esse meio.

Pode ser que esta pesquisa impacte o meio acadêmico, pois reconhecer documentos, evidenciar os métodos quantitativos, qualitativos ou mistos -, além de leis e decretos governamentais que estimulam a pratica do basquetebol, ao observar uma amostra de quais tipos de estudos e leis existem e fortalecem o meio, pode vir a colaborar com as organizações que detêm a modalidade, tornando-se um estudo de utilidade por possibilitar outros conhecimentos (Thomas \& Nelson, 2009; Esporte, 2021).

A trajetória educacional, acadêmica e esportiva do atleta de basquetebol é algo notável que pode ser iniciada em ambientes formais, não formais e informais, escolas, praças públicas e clubes, prováveis ambientes extraordinários, sejam positivos ou negativos, que podem vir a impactar na trajetória esportiva do atleta de basquetebol, e já existem instrumentos validados que tentam compreender esses fenômenos (Libâneo, 2001; Oliveira et al., 2020).

Entender os documentos analisados, os processos de transição do atleta de basquetebol jovem, em que se compreende existir as primeiras experiências de sua trajetória esportiva até que se chegue nas etapas finais das categorias de base foi o objetivo deste trabalho. Pesquisas desse meio apresentaram dados e evidências do ambiente esportivo, principalmente nos anos finais de sua trajetória educacional, esportiva ou transição de carreira esportiva, sem se esquecer do início, do ambiente onde se aprende a gostar do esporte.

O primeiro ambiente, em que a criança ou o adolescente se engaja na carreira esportiva, parece ter elevada importância. Seu início tende a ser na família, uma espécie de microciclo, algo que há de ser fundamental para o desenvolvimento do indivíduo, quando há maiores condições estruturais, financeiras e afetivas fazendo parte de diversas etapas do desenvolvimento humano, dados obtidos nos estudos encontrados (Santos et al., 2020).

Entretanto, as diversas etapas sob o olhar Bioecológico vem sendo retratado para o ambiente esportivo como; esporte na escola, esporte no clube, mudança de nível de competições, mudança para outras equipes, finalização da última categoria de basquete, que é a categoria sub 19 até chegar no sub 22, nesta idade a transição para o esporte profissional, ou seja, existem etapas que podem estar relacionadas dentro da teoria de Bronfenbrenner, que estão interligadas na pessoa, no processo, no contexto e no tempo (PPCT), onde o desenvolvimento do atleta tende a receber influência de um ecossistema. (Koller \& Carvalho, 2011; Oliveira et al., 2020).

Um exemplo deste ambiente Bioecológico seria uma das etapas esportivas, ela inicia-se na escola, se essa etapa for adequada nos conceitos esportivos, pode vir a ter um engajamento maior e uma melhor compreensão do paradoxo da trajetória esportiva, visto que na escola existe um ambiente imensurável na identificação de possíveis talentos do esporte, neste caso o basquetebol. (Krebs, 2006; Santos et al., 2020; Oliveira et al., 2020). 
Foram vistos documentos pontuais que trazem informações principalmente sobre o ambiente esportivo, sobre leis que ajudam e colaboram financeiramente em nível municipal, estadual e nacional. Para esse estudo foram utilizadas as seguintes perguntas norteadoras:

Quais são os estudos que trazem evidências, análises de jovens atletas de basquetebol, em sua trajetória educacional e esportiva? Quais ações governamentais geram impacto nesta trajetória? Quais objetivos, métodos e discussões foram observados nesses estudos? Existe algum tipo de lei governamental que favoreça o atleta de basquetebol em sua trajetória educacional e esportiva? É possível mapear estudos que analisem a trajetória educacional e esportiva de jovens atletas de basquetebol?

Ao discorrer sobre os resultados, em nossa análise é possível que o leitor transite entre diversos tipos de ambientes, pois esses documentos produzidos em locais também distintos oferecem muitas semelhanças em seus métodos e objetivos e possuem um retrato fidedigno do fenômeno estudado, possibilitando responder a todos os objetivos mencionados.

\section{Metodologia}

Este estudo foi desenvolvido a partir de uma revisão de escopo que utilizou a metodologia elaborada pelo Instituto Joanna Briggs (JBI), objetivando mapear estudos que analisem a trajetória educacional, acadêmica e esportiva de jovens atletas de basquetebol, no período de janeiro de 2011 a janeiro de 2021, registrados nas bases de dados Periódicos CAPES, BVS, SciELO, SportDiscus, Scopus, Web of Science, PubMed/ MEDLINE e ERIC (Quadro 01).

O método permite identificar os tipos de evidências disponíveis em um determinado campo ou identificar as principais características ou fatores relacionados a um conceito. Para a construção da pergunta de pesquisa, utilizou-se a estratégia Population, Concept e Context (PCC) para uma scoping review.

Para compor a demonstração desta revisão foi feita uma extração de dados das características bibliográficas, tipos de intervenção, instrumentos utilizados, metodologias utilizadas e principais variáveis dos estudos eleitos.

Os estudos foram incluídos a partir de protocolos de revisão propostos pelo JBI, pesquisadas na semana de 14 a 22 de julho de 2021, e seguiu o processo natural de rastreio de documentos, com uma pesquisa nas bases de dados considerando os descritores "desenvolvimento humano, basquetebol e ambiente educativo", usando os operadores booleanos 'AND' e 'OR'. Foram considerados todos os tipos de pesquisa.

Para fins de transparência do documento, foi anexada na plataforma Open Science Framework (OSF) e está aberta aos demais pesquisadores que tenham intenção em obter mais conhecimento sobre o tema pesquisado (Rocha et al., 2021).

\section{Critérios de inclusão e de exclusão:}

Inclusão: artigos originais, artigos de revisão em português, inglês ou espanhol, nos últimos 10 anos, teses e dissertações (quantitativos e qualitativos), capítulos e livros.

Exclusão: artigos que não tenham títulos semelhantes ao tema, artigos anteriores a 10 anos ou em duplicata e a literatura cinzenta que não esteja em consonância com os objetivos específicos da revisão.

Por fim, os resultados dessa revisão estarão dispostos em tabelas para serem discutidos e analisados logo a seguir. 
Quadro 1 - Bases de dados utilizadas no estudo junto aos operadores booleanos.

\begin{tabular}{|c|c|}
\hline SCIELO & BVS \\
\hline ERIC & SPORTS DISCUS \\
\hline PERIÓDICOS CAPES & SCOPUS \\
\hline WEB OF SCIENCE & PUBMED/ MEDLINE \\
\hline \multicolumn{2}{|c|}{ Operadores booleanos: “AND” “OR” } \\
\hline
\end{tabular}

Fonte: Rocha et al. (2021).

\section{Resultados e Discussão}

Foram encontrados artigos como maioria dos documentos. Tais documentos relataram em suas observações da problemática o ambiente como fator impactante pelos estímulos desfavoráveis e favoráveis relacionados à estrutura esportiva, financeira e educativa. Além desses documentos, seletivamente foram evidenciados documentos que apresentaram leis de apoio ao esporte em nível, municipal, estadual e nacional e que autorizam as entidades esportivas e atletas a conseguir recursos financeiros, de onde espera-se que tais recursos ajudem o ambiente, a trajetória esportiva e a carreira esportiva associadas a esse ambiente. O quadro dois exibe as bases de dados pesquisadas e a quantidade de documentos encontrados, além de apresentar os resultados quantitativos das buscas de documentos onde seguiu-se em sua organização pelos excluídos/título, excluídos/ resumo, excluídos após a leitura na integra e no bloco final a quantidade total de excluídos.

Quadro 2 - Fase de busca realizada nas bases de dados, fase de selecionamento até os documentos excluídos e eleitos.

\begin{tabular}{|c|c|}
\hline BASE DE DADOS & QUANTIDADE \\
\hline SCOPUS & 7 \\
\hline SCIELO & 2 \\
\hline WEB OF SCIENCE & 56 \\
\hline PERÍODICOS CAPES & 102 \\
\hline SPORTDISCUS & 70 \\
\hline PUBMED/MEDLINE & 17 \\
\hline ERIC & 33 \\
\hline BVS & 10 \\
\hline TOTAL DE DOCUMENTOS ENCONTRADOS & 297 \\
\hline FORMAS DE EXCLUSÃO E ELEIÇÃO & 267 \\
\hline Excluídos por título & 14 \\
\hline Excluídos pelo resumo & 7 \\
\hline Excluídos com a leitura na íntegra & 9 \\
\hline Eleitos & 288 \\
\hline Total & \\
\hline
\end{tabular}

Fonte: Rocha et al. (2021).

Foram intencionalmente selecionados documentos governamentais de leis que beneficiam atletas e projetos esportivos a nível de região, estado e Brasil que fortalecem o ambiente do basquetebol descritos abaixo nos quadros explicativos, pois nota-se que recursos que estão indo para projetos da modalidade basquetebol podem contribuir favoravelmente ao ambiente.

Esses documentos, intencionalmente selecionados, servem como exemplo para compreender a existência e o apoio governamental em diversos níveis dentro da cidade de Curitiba, do Estado do Paraná, do Estado de São Paulo e do Brasil. $\mathrm{O}$ quadro três trata da lei municipal de incentivo ao esporte da cidade de Curitiba, organizada pela Secretaria Municipal de Esporte, Lazer e Juventude, que anualmente abre edital para diversos esportes olímpicos/paraolímpicos para beneficiar pessoas físicas e jurídicas. 
Quadro 3 - Lei de incentivo municipal ao esporte da cidade de Curitiba, Paraná.

\begin{tabular}{|c|c|c|c|}
\hline Instituição organizadora & Ano & Aprovados & $\begin{array}{c}\text { Ano de implantação da } \\
\text { lei }\end{array}$ \\
\hline $\begin{array}{c}\text { Lei de incentivo Municipal da cidade de } \\
\text { Curitiba pessoa Jurídica e pessoa física }\end{array}$ & $2020 / 2021$ & 5 & 2002 \\
\hline
\end{tabular}

Fonte: Prefeitura (2021), adaptado por Rocha et al. (2021).

No ano de 2020, com execução no ano 2021, 5 projetos de atletas e entidades foram aprovados pela Lei Municipal de Incentivo ao Esporte da cidade de Curitiba na modalidade basquetebol, fazendo com que se observe a necessidade de que mais projetos sejam desenvolvidos para fomentar a modalidade na cidade.

A população estimada da cidade de Curitiba, Paraná em 2021, segundo o IBGE (2021), será de 1 milhão e 963 mil pessoas, de acordo com o último censo. Ou seja, a cada 392 mil pessoas existe um projeto de basquetebol, para pessoa física ou pessoa jurídica (IBGE Curitiba, 2021).

O quadro quatro apresenta projetos em trâmite de aprovação do Estado do Paraná, com recursos do ICMS (Imposto sobre Circulação de Mercadorias e Serviços). Foram apenas eleitos projetos que são ligados ao basquetebol, para pessoa jurídica, todavia pessoas físicas foram contempladas, mas sem a possiblidade de identificar a modalidade apresentada, apenas o nome da pessoa e o $\mathrm{n}^{\circ}$ do protocolo são visíveis para os espectadores. Devido a isso, foi excluída a análise de pessoa física.

Quadro 4 - Lei de incentivo do estado do Paraná por meio do imposto sobre circulação de mercadorias e serviços.

\begin{tabular}{|c|c|c|c|}
\hline Instituição organizadora & Ano & Pré-aprovados & Ano de implantação \\
\hline $\begin{array}{c}\text { Lei de incentivo Estadual (ICMS) em fase de } \\
\text { aprovação de projetos para basquetebol } \\
\text { pessoa Jurídica }\end{array}$ & $2021 / 2022$ & 5 & 2013 \\
\hline
\end{tabular}

Fonte: Paraná (2021), adaptado por Rocha et al. (2021).

Projetos incentivados em nível estadual, nota-se comparando-se ao tamanho do Estado do Paraná um montante pequeno de projetos pré-aprovados que tenham objetivos de favorecer a modalidade basquetebol. No quadro cinco são apresentados projetos aprovados da Geração Olímpica do Estado do Paraná, que beneficiam atletas e técnicos do estado divididos em categorias.

Quadro 5 - Projeto do estado do Paraná geração olímpica com a quantidade de atletas e técnicos incentivados ano 2021

\begin{tabular}{|c|c|c|}
\hline $\mathbf{2 0 2 1}$ & $\mathbf{2 0 2 1}$ & $\mathbf{2 0 2 1}$ \\
\hline Aprovação & Aprovação & Aprovação \\
\hline Categoria Olimpo & Categoria Estadual primeira lista & Categoria Estadual segunda lista \\
\hline 0 & 45 & \\
\hline $\begin{array}{c}\text { O basquetebol esteve fora das olímpiadas de } \\
\text { Tóquio/ Japão }\end{array}$ & & \\
\hline
\end{tabular}

Fonte: Paraná (2021), adaptado por Rocha et al. (2021).

Os projetos da Geração Olímpica promovidos pelo Estado do Paraná são modelos de destaque em nível nacional um colaborador para atletas e técnicos em evidência, é por meio desta lei que eles recebem recursos financeiros para os ajudar a ter melhores condições em treinos, viagens e competições esportivas, neste caso foi descrito no quadro cinco apenas os da modalidade basquetebol.

O quadro seis apresenta a Lei de incentivo ao esporte do Estado de São Paulo, documento eleito intencionalmente para ser comparado aos projetos do estado do Paraná. 
Quadro 6 - Lei de incentivo ao esporte do estado de São Saulo, Brasil.

\begin{tabular}{|c|c|c|c|}
\hline $\begin{array}{c}\text { Lei Paulista de Incentivo ao } \\
\text { Esporte/ Basquetebol ano 2020 }\end{array}$ & Categorias & $\begin{array}{c}\text { Estado de São } \\
\text { Paulo }\end{array}$ & $\begin{array}{c}\text { Ano de } \\
\text { implantação }\end{array}$ \\
\hline $\begin{array}{c}\text { Projetos como: } 3 \times 3 \text { e basquete } \\
\text { convencional }\end{array}$ & $\begin{array}{c}\text { 1 2 Educacional } \\
\text { Formação esportiva } \\
\text { 4 Rócio desportiva }\end{array}$ & 63 & 2010 \\
\hline
\end{tabular}

Fonte: São Paulo (2021), adapatado por Rocha et al. (2021).

Quadro 7 - Comparação da lei de incentivo ao esporte do estado do Paraná x estado de São Paulo, comparando o número de habitantes por projetos

\begin{tabular}{|c|c|c|c|}
\hline PROJETOS ICMS PARANÁ X SÃO PAULO & PROJETOS & $\begin{array}{c}\text { HABITANTES POR } \\
\text { ESTADO }\end{array}$ & HABITANTES \\
\hline $\begin{array}{c}\text { Projetos pré-aprovados ICMS Paraná ano 2021 } \\
\text { modalidade basquetebol }\end{array}$ & 5 & 11 milhões & $\begin{array}{c}2 \text { milhões e } 200 \text { mil } \\
\text { habitantes }\end{array}$ \\
\hline $\begin{array}{c}\text { Projetos aprovados ICMS São Paulo ano 2020 } \\
\text { modalidade basquetebol }\end{array}$ & 63 & 44 milhões & $\begin{array}{c}698 \text { mil e } 412 \\
\text { habitantes }\end{array}$ \\
\hline & & & \\
\hline
\end{tabular}

Fonte: IBGE (2021), adaptado por Rocha et al. (2021).

Foi realizado um estudo comparativo teórico, por meio do IBGE (2021), onde ficou elucidado que a cada 2 milhões de habitantes do Estado do Paraná existe um projeto pré-aprovado da modalidade basquetebol no ano de 2021 para obter recursos do ICMS, enquanto que no estado de São Paulo a cada 698 mil habitantes existe um projeto de basquetebol aprovado e executado por meio da lei de incentivo Paulista do retorno do ICMS no ano de 2020.

Quadro 8 - Resultados de projetos em nível nacional com sua classificação de $1^{\circ}$ a $4^{\circ}$ lugar, quantidade de projetos aprovados por região do brasil e quantidade de pessoas beneficiadas.

\begin{tabular}{|l|c|c|c|c|}
\hline \multicolumn{1}{|c|}{ PROJETOS } & $\begin{array}{c}\text { MAIS SOLICITADOS } \\
\text { NA LIE }\end{array}$ & $\begin{array}{c}\text { QTDA DE PROJETOS } \\
\text { A NÍVEL BRASIL } \\
\text { EXECULTADOS }\end{array}$ & REGIÃO & $\begin{array}{c}\text { PESSOAS } \\
\text { BENEFICIADAS POR } \\
\text { MEIO DE TODAS } \\
\text { MODALIDADES } \\
\text { ESPORTIVAS }\end{array}$ \\
\hline Futebol & $1^{\mathbf{o}}$ & 01 & Norte & \multirow{2}{*}{202 mil } \\
\hline Vôlei & $2^{\mathbf{o}}$ & 10 & Nordeste & \\
\hline Atletismo & $3^{\text {o }}$ & 03 & Centro Oeste & \\
\hline Basquetebol & $4^{\mathbf{o}}$ & 136 & Sudeste & Sul \\
\hline Total & & 34 & & \\
\hline
\end{tabular}

Fonte: Cidadania (2021), adaptado Rocha et al. (2021).

No Quadro 8 procurou-se descrever a nível Brasil por meio do desfecho da Lei de Incentivo Federal ao Esporte, Lei ${ }^{\circ}$ 11.438 de 2006 - (LIE) e seus resultados 14 anos após sua criação, impactando não apenas no basquetebol, e sim em todas as modalidades olímpicas atuais do Brasil. Além de atuar como instrumento de inclusão social, uma vez que a prática desportiva auxilia na diminuição de despesas governamentais com saúde; ela coopera com a segurança pública, ao diminuir níveis de violência por meio de projetos esportivos incentivados em localidades de ausência esportiva (Cidadania, 2021). 


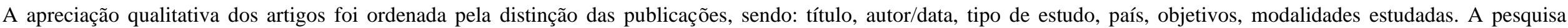
analisou 9 artigos, organizados no quadro a seguir:

Quadro 9 - Organização dos documentos eleitos em ordem de ano de publicação crescente evidenciando autor/ data/tipo de estudo/país/objetivos/modalidades estudadas.

\begin{tabular}{|c|c|c|c|c|c|c|}
\hline $\mathbf{N}^{\circ}$ & TÍTULO & AUTOR/DATA & $\begin{array}{l}\text { TIPO DE } \\
\text { ESTUDO }\end{array}$ & PAÍS & OBJETIVOS & $\begin{array}{l}\text { MODALIDADES } \\
\text { ESTUDADAS }\end{array}$ \\
\hline 1 & $\begin{array}{l}\text { A resiliência no âmbito esportivo: } \\
\text { uma perspectiva bioecológica do } \\
\text { desenvolvimento humano }\end{array}$ & $\begin{array}{c}\text { Rita de Cássia da Costa } \\
\text { Fontes, Maria Regina Ferreira } \\
\text { Brandão } \\
\mathbf{2 0 1 3}\end{array}$ & $\begin{array}{c}\text { Artigo } \\
\text { Este estudo } \\
\text { caracterizou-se } \\
\text { por uma pesquisa } \\
\text { descritiva de } \\
\text { abordagem } \\
\text { qualitativa } \\
\end{array}$ & BRASIL & $\begin{array}{l}\text { O objetivo desse estudo foi investigar na } \\
\text { perspectiva do paradigma bioecológico a } \\
\text { resiliência no contexto do esporte de alto } \\
\text { rendimento estudando } 7 \text { atletas de basquetebol } \\
\text { que já estiveram em nível mundial de } \\
\text { competição. }\end{array}$ & $\begin{array}{l}\text { ESPORTE DE ALTO } \\
\text { RENDIMENTO }\end{array}$ \\
\hline 2 & $\begin{array}{l}\text { Dream Chasers: An Exploration of } \\
\text { How Role Identity Is Related to } \\
\text { Career Development Attitudes } \\
\text { among African American Male } \\
\text { Collegiate Athletes }\end{array}$ & $\begin{array}{l}\text { Charles Lamar Small } \\
\mathbf{2 0 1 3}\end{array}$ & $\begin{array}{l}\text { Dissertação } \\
\text { Estudo } \\
\text { Qualitativo }\end{array}$ & EUA & $\begin{array}{l}\text { Este estudo foi projetado para explorar como a } \\
\text { identidade do papel está relacionada às atitudes } \\
\text { de desenvolvimento de carreira entre } \\
\text { estudantes-atletas universitários do sexo } \\
\text { masculino afro-americano. }\end{array}$ & BASQUETEBOL \\
\hline 3 & $\begin{array}{l}\text { Psychosocial Factors Involved in } \\
\text { Transitions from College to } \\
\text { Postcollege Careers for Male NCAA } \\
\text { Division-1 Basketball Players }\end{array}$ & $\begin{array}{l}\text { Paul Cummins, Ian O’Boyle } \\
2015\end{array}$ & $\begin{array}{l}\text { Estudo } \\
\text { Qualitativo }\end{array}$ & AUSTRÁLIA & $\begin{array}{l}\text { O objetivo foi de investigar os principais } \\
\text { fatores psicossociais que impactam os } \\
\text { jogadores de basquete do sexo masculino da } \\
\text { National Collegiate Athletic Association } \\
\text { (NCAA) Divisão-1. }\end{array}$ & $\begin{array}{l}\text { BASQUETEBOL } \\
\text { UNIVERSITÁRIO }\end{array}$ \\
\hline 4 & $\begin{array}{l}\text { Personal attributes of female } \\
\text { basketball athletes in training }\end{array}$ & $\begin{array}{l}\text { Alexandra Folle, Valmor } \\
\text { Ramos, Juarez Vieira do } \\
\text { Nascimento } \\
\mathbf{2 0 1 5}\end{array}$ & $\begin{array}{l}\text { Pesquisa } \\
\text { descritiva com } \\
\text { abordagem } \\
\text { qualitativa }\end{array}$ & BRASIL & $\begin{array}{l}\text { Teve como objetivo examinar os atributos } \\
\text { pessoais de atletas pertencentes a um clube de } \\
\text { destaque na área de desenvolvimento de atletas } \\
\text { de basquete feminino. }\end{array}$ & BASQUETEBOL \\
\hline 5 & $\begin{array}{l}\text { Basquetebol feminino de excelência: } \\
\text { desenvolvimento de carreira de } \\
\text { atletas brasileiras campeãs mundiais } \\
\text { e medalhistas olímpicas }\end{array}$ & $\begin{array}{l}\text { Larissa Rafaela Galatti, } \\
\text { Renato Francisco Marques, } \\
\text { Carlos Eduardo Barros, } \\
\text { Antonio Montero Seoane, } \\
\text { Roberto Rodrigues Paes } \\
\mathbf{2 0 1 5} \\
\end{array}$ & $\begin{array}{c}\text { Artigo } \\
\text { A metodologia é } \\
\text { o discurso do } \\
\text { Sujeito Coletivo } \\
\text { Pesquisa } \\
\text { Qualitativa } \\
\end{array}$ & BRASIL & $\begin{array}{l}\text { O objetivo foi identificar os múltiplos fatores } \\
\text { do indivíduo que o influenciaram a atingir o } \\
\text { nível de excelência } \\
\text { ao longo de sua carreira esportiva. }\end{array}$ & BASQUETEBOL \\
\hline 6 & $\begin{array}{ll}\text { Female Basketball Athlete } \\
\text { Development } & \text { Environment: } \\
\text { Proposed Guidelines } & \text { and Success } \\
\text { Factors } & \end{array}$ & $\begin{array}{l}\text { Folle, Alexandra; Vieira do } \\
\text { Nascimento, Juarez; Souza, } \\
\text { Edison Roberto de; Galatti, } \\
\text { Larissa Rafaela; Graça, } \\
\text { Amândio } \\
\mathbf{2 0 1 7} \\
\end{array}$ & $\begin{array}{l}\text { Artigo } \\
\text { Pesquisa } \\
\text { descritiva com } \\
\text { abordagem } \\
\text { qualitativa }\end{array}$ & BRASIL & $\begin{array}{l}\text { O objetivo do estudo é analisar as diretrizes e } \\
\text { os fatores de sucesso de um clube esportivo que } \\
\text { contribuem para a identificação e o } \\
\text { desenvolvimento das jogadoras de basquete. }\end{array}$ & BASQUETEBOL \\
\hline
\end{tabular}


Research, Society and Development, v. 10, n. 16, e94101623498, 2021

(CC BY 4.0) | ISSN 2525-3409 | DOI: http://dx.doi.org/10.33448/rsd-v10i16.23498

\begin{tabular}{|c|c|c|c|c|c|c|}
\hline 7 & 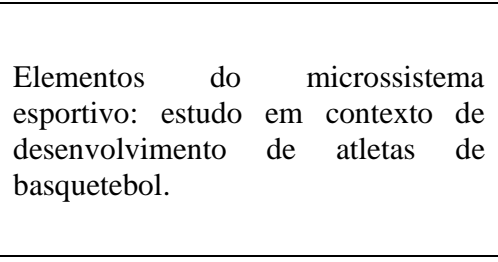 & $\begin{array}{c}\text { Folle, Alexandra; Nascimento, } \\
\text { Juarez V. do; Guimarães, } \\
\text { Juliana R. S; Nascimento, } \\
\text { Raquel K. do; Marinho, } \\
\text { Alcyane; Farias, Gelcemar } \\
\text { Oliveira } \\
\mathbf{2 0 1 7} \\
\end{array}$ & $\begin{array}{c}\text { Artigo } \\
\text { Pesquisa } \\
\text { descritiva com } \\
\text { abordagem } \\
\text { qualitativa }\end{array}$ & BRASIL & $\begin{array}{l}\text { Buscou identificar os elementos do } \\
\text { microssistema que contribuem para o processo } \\
\text { de desenvolvimento de atletas de basquetebol. }\end{array}$ & BASQUETEBOL \\
\hline 8 & $\begin{array}{l}\text { Envolvimento dos familiares no } \\
\text { processo de formação esportiva no } \\
\text { basquetebol feminino }\end{array}$ & $\begin{array}{c}\text { Alexandra FolleJuarez, Vieira } \\
\text { do Nascimento, William das } \\
\text { Neves Salles, } \\
\text { Larissa Fernanda Porto, } \\
\text { Maciel Eduardo José } \\
\text { Dallegrave } \\
\mathbf{2 0 1 8} \\
\end{array}$ & $\begin{array}{c}\text { Artigo } \\
\text { Pesquisa } \\
\text { descritiva com } \\
\text { abordagem } \\
\text { qualitativa }\end{array}$ & BRASIL & $\begin{array}{l}\text { O objetivo do estudo foi analisar o } \\
\text { envolvimento de familiares no processo de } \\
\text { desenvolvimento esportivo de } 31 \text { atletas de } \\
\text { basquete feminino pertencentes a um clube } \\
\text { esportivo no estado de Santa Catarina / Brasil. }\end{array}$ & BASQUETEBOL \\
\hline 9 & $\begin{array}{l}\text { Trajetória no basquetebol e perfil } \\
\text { sociodemográfico de atletas } \\
\text { brasileiras ao longo da carreira: um } \\
\text { estudo com a liga de basquete } \\
\text { feminino (lbf) }\end{array}$ & $\begin{array}{c}\text { Larissa Rafaela Galatti } \\
\text { Cesar Vieira Marques Filho } \\
\text { Yura Yuka Sato dos Santos } \\
\text { Guilherme Watoniki } \\
\text { Paula Korsakas } \\
\text { Luciano Allegretti Mercadante } \\
\text { 2021 }\end{array}$ & $\begin{array}{l}\text { Artigo } \\
\text { Estudo de Caso } \\
\text { Pesquisa } \\
\text { Qualitativa }\end{array}$ & BRASIL & $\begin{array}{l}\text { O objetivo do estudo foi investigar indicativos } \\
\text { esportivos e sociodemográficos ao longo da } \\
\text { carreira de atletas da LBF } 2018 \text {. }\end{array}$ & BASQUETEBOL \\
\hline
\end{tabular}

Fonte: Rocha et al. (2021) 
A investigação ocorreu nas bases de dados que apresentaram estudos sobre a trajetória educacional/esportiva de jovens atletas de basquetebol. Seguiu-se a ela um ponto inicial para encontrar os estudos específicos retratando a problemática. O ponto inicial partiu dos descritores "ambiente educativo, desenvolvimento humano e basquetebol", que proporcionaram um caminho aberto, no qual os pesquisadores elegeram 9 artigos que descreviam os ambientes do basquetebol e o desenvolvimento dos atletas, sendo possível conhecer os autores, quais foram os processos temporais, de qual "locus" vem sendo pesquisado sobre esse fenômeno e suas variáveis.

Foram selecionados intencionalmente documentos que trazem leis que aportam com recursos financeiros, atletas, técnicos e entidades, pois compreende-se que esses apoios podem também impactar o meio esportivo favoravelmente, com observações sobre sua carreira esportiva ou trajetória educacional/esportiva na modalidade basquetebol.

Foram observados estudos de atletas jovens em algum tipo de transição, tais como mudança de categoria, por exemplo, do sub-19 para o adulto, mudança de nível na universidade, onde os atletas dos últimos anos se profissionalizaram e grande parte deles foram excluídos do sistema, interrompendo sua trajetória ou carreira esportiva, podendo ser encarado com uma espécie de desequilíbrio desse ambiente (Fontes \& Brandão, 2013; Small, 2013; Cummins \& O’boyle, 2015; Folle, Ramos \& Nascimento, 2015; Galatti et al., 2015; Folle et al., 2017; Folle et al., 2018; Galatti et al., 2021).

O Fluxograma 1 reflete uma espécie de sinergia dos ambientes conectando também aos ambientes formais, informais e não formais.

Fluxograma 1 - Retrata a fase de transição da trajetória esportiva até um possível desfecho.

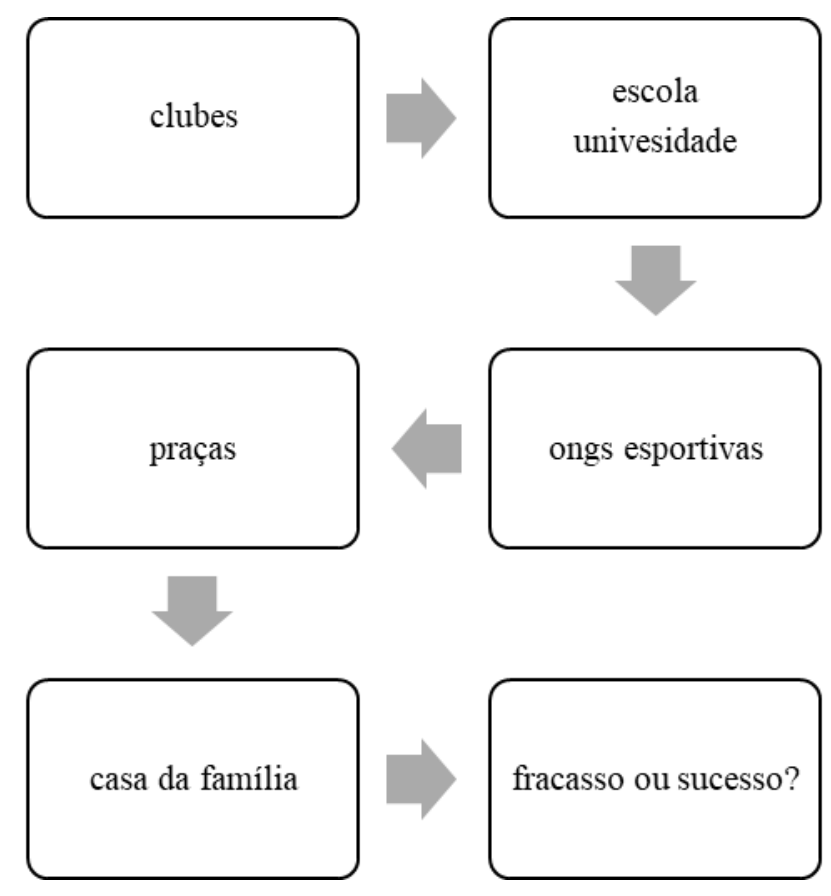

Fonte: Rocha et al. (2021).

Os estudos encontrados foram organizados em ordem de publicação crescente, começando pelo ano de 2013 e se estendendo até o ano de 2021. Foram achados artigos e teses como os principais documentos analisados que têm o basquetebol como ambiente como maior ênfase e o esporte de rendimento como segundo plano. A maioria dos estudos aconteceu no Brasil, seguindo para os Estados Unidos e Austrália em segundo plano.

Foram intencionalmente selecionados documentos que retratam a lei municipal da cidade de Curitiba de incentivo ao esporte, a Lei do estado do Paraná de Incentivo ao Esporte e a lei Federal de Incentivo ao Esporte do Ministério da Cidadania. 
Para Fontes et al., (2013), seus resultados apontam que o ambiente esportivo pode impactar na trajetória do atleta, e destaca alguns aspectos, como a resiliência, que é preciso ser desenvolvida nos atletas de alto rendimento para suportar pressões intrínsecas e extrínsecas. Consequentemente, o atleta que recebe estrutura e apoio familiar, escolar e do clube convive com aspectos favoráveis.

Concorda-se com Fontes et al., (2013) de que é necessário distintos níveis e tipos de apoio para conseguir se manter no esporte de alto rendimento, além de ser fator positivo nessa trajetória o ambiente favorável com o professor, que segue todas etapas do atleta. Entretanto, em outros estudos encontrados viu-se outros tipos de desafios proporcionados pelo ambiente e pela cultura no sistema existente.

Observa-se, indo ao encontro de Fontes et al., (2013), que neste estudo, em que se avaliou que atletas afro-americanos na universidade tinham outros desafios para conseguir permanecer na transição de carreira universitária no esporte, e nota-se que há muitas barreiras para a continuidade do atleta de basquetebol afro-americano, mesmo eles sendo a grande maioria jogando basquetebol, muitos desistem na transição para níveis para se alcançar a carreira esportiva.

Este estudo trouxe dados analisados de pessoas que alcançaram uma identidade estável e tendem a usar estratégias racionais e sistemáticas de decisão de carreira (Small, 2013).

É possível que esse atleta esteja no basquetebol universitário, e por meio dele pode haver mais chances de conseguir uma carreira no esporte, e do lado humano um estímulo para tomar decisões e melhorar seu autoconceito pessoal.

Tanto Fontes et al., (2013) quanto Small (2013) fizeram suas pesquisas em locais diferentes com propósitos distintos, porém existe uma semelhança: eles estão sendo influenciados pelo ambiente, podendo concluir que de alguma forma nesses estudos existe um impacto que movimenta a vida dos atletas.

O estudo de Cummins e O’Boyle (2015) comparou as transições bem e mal sucedidas em todos os estágios do desenvolvimento atlético e trouxe evidências, fatores que estão influenciando nesse processo em que 3500 estudantes da divisão 1 NCAA (National Collegiat Athletic Association) do Basketball são encurralados para se fazer a transição de carreira onde a porcentagem alarmante de $98 \%$ para devido à exclusão profissional e são impactados em sua maioria com experiências traumáticas (Cummins \& O’boyle, 2015).

Um estudo relata que as transições de níveis esportivos podem ser observadas em fatores psicossociais como sendo extraordinárias, nas mudanças que ocorrem após a formação universitária do atleta, aonde muitos param nesse momento, e poucos continuam até serem bem-sucedidos ou não, pois neste caminho do atleta de basquetebol também existem fatores como lesões, oportunidades que favorecem e capacidades individuais que os levam a caminhos distintos do sucesso ou do fracasso esportivo, porém existem múltiplos motivos do abandono da carreira esportiva, contudo a falta de estrutura é a mais observada neste estudo, muitos experienciando vivências negativas e traumáticas, segundo Cummins e O'Boyle (2015).

Apesar de métodos diferentes, existem semelhanças nas pesquisas. Nota-se no ambiente o processo de transição, observando-se cargas principalmente emocionais que existem, muitas delas não sendo favoráveis. A falta de estrutura no Brasil por meio dos estudos de Fontes et al., (2013), e do estudo nos EUA de Cummins e O'boyle (2015) se toma como evidência no final do processo de transição de carreira atlética a falta de um programa equilibrado que não excluiria 98\%, seus atletas podendo existir outras oportunidades, como a exclusão de forma inesperada podendo ser um fator significativo para seu desenvolvimento humano.

Já no estudo de Folle, Ramos e Nascimento (2015) fica clara a presença do ambiente esportivo, nesse caso foi utilizada a Teoria Bioecologica de Urie Bronfenbrenner, que respalda um questionário em que suas respostas foram sobre estímulos positivos e negativos na trajetória esportiva da atleta de basquetebol, colaborando com a maioria dos autores pesquisados, onde relatam que os atletas estão sendo influenciados pelo ambiente esportivo (Folle et al.,2015). 
Ao nosso olhar, vamos ao encontro das evidências já vistas, onde pesquisas de grande importância estão relatando que existem forças que transcendem e que podem agir em momentos favoráveis e menos favoráveis na trajetória educacional/ esportiva, compreendendo assim o esporte que inicia na família, sendo a escola o maior estímulo para essa prática.

Nos estudos de Galatti et al., (2015), em pesquisas sobre atletas de basquetebol medalhistas Olímpicas, evidenciou-se que o sucesso obtido na época, os que eram da base, têm relação com a prática e autonomia diversificada para o desenvolvimento das jogadoras nos primeiros anos de suas carreiras esportivas, assim como o apoio financeiro nos anos de especialização do esporte. Ainda se compreende que após anos de investimento e manutenção as habilidades intrapessoais tornaram-se mais importantes, o tempo de treinamento aumentou e houve um descaso com o convívio social, fazendo referência ao momento atual. E a falta de sucesso do basquete feminino brasileiro é causada por; não existir aquela estrutura de outras épocas; e existe uma concorrência social que impede as meninas de se comprometerem com a vida de atleta, com dedicação e abnegação.

A identificação de elementos do microssistema que contribuiu para o processo de desenvolvimento abordou temas como a motivação e a desmotivação nos treinamentos, nível de relacionamento com treinadores e colegas, acompanhamento de jogo, admiração no meio esportivo, contato social, nível de exigência, nível de dedicação, incentivo de valorização demonstrados pelos técnicos e outras relações, evidenciando um estudo importante que relaciona o ambiente como fator fundamental no desenvolvimento de atletas de basquetebol que buscam ter sucesso em sua trajetória esportiva (Folle, 2017).

É fato que os estudos são distintos, contudo existem muitas semelhanças, principalmente no momento de transição dos atletas, onde parece existir diferentes cargas que irão impactar no sucesso ou fracasso, porém tal processo parece ser inevitável.

Folle (2018) destacou em sua pesquisa a importância da família no processo de formação de atletas de basquetebol do sexo feminino, esse processo e todo contexto onde se tem fatores motivacionais que favorecem a atleta, destacando o papel fundamental da família, que está ligada à escola e ao clube, reconhecendo que os filhos precisam de respaldo para ter mais engajamento no esporte.

Já nos estudos de Gallati et al., ( 2021) a liga de basquetebol feminina do Brasil serviu como um grande laboratório para pesquisar atletas femininas que têm sua trajetória esportiva marcada por um contexto da realidade brasileira após os anos 2000 cheia de desafios, pois anteriormente as seleções tiveram algum tipo de sucesso em competições internacionais, e o ponto que chama atenção é que a região Sudeste do Brasil é a que concentra mais resultados com a modalidade em aspectos de quantidade de atletas, maior estrutura e maior engajamento nas seleções por atletas que estão nessa região.

De todas as atletas que participaram da Liga de basquetebol feminino, 79\% chegaram às seleções de base, porém apenas 30\% vestiu a camiseta da seleção Brasileira adulta. Outra variável de destaque foi o nível escolar das jogadoras, acima da média da população brasileira, podendo evidenciar que estar jogando basquetebol é sinal de estar estudando efetivamente e com notas boas (Galatti, et al., 2021).

A maioria dos documentos encontrados apresentaram método de pesquisa qualitativa que utilizaram-se de perguntas semiestruturadas, questionários se apoiando na teoria Bioecologica adaptada aos esportes para tentar compreender a influência do ambiente no desenvolvimento humano dos atletas, indo ao encontro de Oliveira et al., (2020).

\section{Conclusão}

Esta scoping review retratou um pouco o ambiente do basquetebol em seu formato documental, dando a conhecer uma quantidade razoável de documentos que analisam a trajetória educacional/ esportiva e a carreira do atleta, observando o desenvolvimento humano e o ambiente educacional e esportivo. Todas as perguntas norteadoras foram respondidas assim 
como os objetivos foram alcançados, podendo-se ter neste estudo um norte para se conhecer alguns pesquisadores e diversos de seus objetivos de pesquisa que possam facilitar a compreensão deste ambiente.

Existiram dificuldades em encontrar documentos que estudem, analisem e pesquisem o tema discutido nas organizações de maior interesse do basquetebol, a Federação Paranaense de Basketball e a Confederação Brasileira de Basketball, por isso sugere-se que é preciso um estudo mais robusto para tentar encontrar essas evidências.

Foram encontrados em nível regional, estadual e nacional aportes governamentais que auxiliam financeiramente as entidades ligadas ao esporte, atletas e técnicos, sendo um fator fundamental na trajetória educacional/ esportiva desses indivíduos.

Ficou evidente que na comparação de projetos aportados pela lei do (Imposto sobre Circulação de Mercadorias e Serviços) ICMS entre o Estado do Paraná e de São Paulo existe uma grande desvantagem para o Paraná, pois pareceu ser pequena a quantidade de projetos aprovados na modalidade basquetebol no Paraná em comparação com o Estado de São Paulo, associando projetos com a quantidade de habitantes, porém o Paraná ainda é uma das regiões do Brasil onde mais se apoia os esportes via leis de incentivo, se comparado às outras regiões do País. Por meio desses documentos se nota a falta de projetos principalmente na região Norte, Nordeste e Centro-Oeste do Brasil podendo ocasionar a falta de atletas de basquetebol oriundos destas regiões.

A maioria dos estudos encontrados apresentou uso de método de abordagem qualitativa e apresentou semelhança em vários fatores, como ambiente, estrutura, recursos financeiro e transição, seja ela por categoria ou por carreira esportiva. Notase a falta de documentos que se utiliza de métodos quantitativos que utilizam a teoria de Urie Bronfenbrenner, os ambientes do basquetebol apresentados por esses documentos têm semelhanças em seu problema, problemática e método.

\section{Agradecimentos}

Agradecemos a todos que direta ou indiretamente contribuíram para a realização e sucesso do artigo.

\section{Referências}

Cbb, C. B. (2021). CBB. https://cbb.com.br/

Cidadania, M. D. (2021). Creative Commons Atribuição-SemDerivações 3.0 Não Adaptada. https://www.gov.br/cidadania/pt-br/acoes-e-programas/lei-deincentivo-ao-esporte

Cummins, P., \& O’boyle, I. (2015). Psychosocial factors involved in transitions from college to postcollege careers for male NCAA Division-1 basketball players. Journal of Career Development. 42, 33-47. doi 10.1177/0894845314532713

Esporte, P. (2021). Celepar.: https://www.esporte.pr.gov.br/Pagina/Proesporte-Lei-de-Incentivo

Esporte, P. S. (2021). Esportes São Paulo/ São Paulo. https://www.esportes.sp.gov.br/confira-a-lista-de-projetos-aprovados-pela-lpie-em-2020/

Folle, A. e. (2017). Elementos do microssistema esportivo:Estudo em contexto de desenvolvimento de atletas de basquetebol. Rev. bras. ciênc. mov, 106-124. https://pesquisa.bvsalud.org/portal/resource/pt/biblio-880882

Folle, A. e. (2017). Female basketball athlete development environment: proposed guidelines and success factors. Educación Física y Ciencia, 19(2). doi $10.24215 / 23142561 \mathrm{e} 035$

Folle, A., Nascimento, J. V. D., Salles, W. D. N., Maciel, L. F. P., \& Dallegrave, E. J. (2018). Envolvimento dos familiares no processo de formação esportiva no basquetebol feminino. Journal of Physical Education, 29.Folle, A., Ramos, V., \& Nascimento, J. V. (2015). Personal attributes of female basketball athletes in training. Revista Brasileira de Cineantropometria \& Desempenho Humano, 17, 672-682.10.4025/jphyseduc.v29i1.2914

Fontes, R. D., \& Brandão, M. R. (2013). A resiliência no âmbito esportivo: uma perspectiva bioecológica do desenvolvimento humano. Motriz: Revista de Educação Física, 19(1), 151 -159. https://doi.org/10.1590/S1980-65742013000100015

Fprb, F. P. (2021). https://www.basqueteparana.com.br/

Galatti, L. R. (2015). Determinantes de excelência no basquetebol feminino: as conquistas da seleção Brasileira na perspectiva das atletas. Revista da Educação Física/UEM, 26, 621-632. https://doi.org/10.4025/reveducfis.v26i4.26424 
Research, Society and Development, v. 10, n. 16, e94101623498, 2021

(CC BY 4.0) | ISSN 2525-3409 | DOI: http://dx.doi.org/10.33448/rsd-v10i16.23498

Galatti, L. R. (2021). Trajetória no basquetebol e perfil sociodemográfico de atletas brasileiras ao longo da carreira: um estudo com a liga de basquete feminino (lbf). Movimento, 27. https://doi.org/10.22456/1982-8918.106017

Gomes, J. H. (2018). Estado de humor e desempenho físico de jogadores jovens de basquetebol ao longo de uma competição. Journal of Physical Education. https://doi.org/10.4025/jphyseduc.v29i1.2969

Ibge, \& Curitiba. (2021). IBGE. https://cidades.ibge.gov.br/brasil/pr/curitiba/panorama

Koller, S. H., \& Carvalho, A. d. (2011). BRONFENBRENNER, Urie. Bioecologia do desenvolvimento humano: tornando os seres humanos mais humanos. Artmed.

Krebs, R. J. (2006). A Teoria Bioecológica do Desenvolvimento Humano e o contexto da educação inclusiva. Revista da Educação Especial 3, 40-45. http://files.diees-semed.webnode.com/200002004-c2fa4c3f47/revistainclusao2.pdf\#page=40

Libâneo, J. C. (2001). Pedagogia e pedagogos: inquietações e buscas. Educar em Revista, 153-176. https://www.scielo.br/j/er/a/xrmzBX7LVJR Y5pPjFxXQgnS/?format=pdf\&lang=pt

Oliveira, V., Paes, R. R., \& Vagetti, G. (2020). BASQUETEBOL: Pedagogia, Aprendizagem e Desenvolvimento. Londrina/ Paraná: Sport Training. $10.29327 / 515523$

de Oliveira, V., Szeremeta, T., da Silva Gasparotto, G., dos Santos, A. S., Bichels, A., Sikora, G., ... \& Vagetti, G. C. (2020) A carreira esportiva sob o modelo bioecológico de bronfenbrenner: construção e validação interna de instrumento avaliativo. 10.37885/201001880

Parana, E. (2021). Celepar. Geração Olímpica: https://www.esporte.pr.gov.br/Pagina/Geracao-Olimpica

Prefeitura, C. (2021). ICI. https://www.curitiba.pr.gov.br/conteudo/projetos-aprovados/2984

Rocha, A., Corrêa, W., Brun, G., Vagetti, G., \& Valdomiro, O. (2021, novembro). A trajetória educacional, acadêmica e esportiva de jovens atletas de basquetebol: Uma revisão de escopo. OSF. Retrieved (2021, November 18). A trajetória educacional, acadêmica e esportiva de jovens atletas de basquetebol: Uma revisão de escopo. https://doi.org/10.17605/OSF.IO/J45EW, https://osf.io/dashboard

Santos, A. S., \& Bichels, A. e. (2020). Percepção de atletas sobre suas trajetórias no atletismo a partir do Modelo Biecológico de Bronfenbrenner. Educación Física y Deportes, 94-111. https://doi.org/10.46642/efd.v25i264.1763

Small, C. L. (2013). Dream chasers: An exploration of how role identity is related to career development attitudes among African American male collegiate athletes (Doctoral dissertation, University of Pittsburgh). https://www.proquest.com/openview/96354b1625677092b0f5059f6ac07bc0/1?pqorigsite $=$ gscholar $\& \mathrm{cbl}=18750$

Szeremeta, T. P. (2019). Construção e validação de um instrumento de avaliação da trajetória esportiva son a ótica do modelo bioecológico. https://www.acervodigital.ufpr.br/handle/1884/59712

Thomas, J. R., \& Nelson, J. K. (2009). Métodos de pesquisa em atividade física. (6a ed.). Artmed.

Tubino, M. (1999). O que é o esporte: uma enciclopédia crítica (2a ed.), Brasiliense. 